\title{
Effects of Invasive Spartina alterniflora Loisel. and Subsequent Ecological Replacement by Sonneratia apetala Buch.-Ham. on Soil Organic Carbon Fractions and Stock
}

\author{
Jianxiang Feng ${ }^{1}$, Shugong Wang ${ }^{2,3, *}$, Shujuan Wang ${ }^{2,3}$, Rui Ying ${ }^{1}$, Fangmin Yin ${ }^{1}$, Li Jiang ${ }^{1}$ and \\ Zufu Li ${ }^{1}$ \\ 1 School of Life Sciences, Sun Yat-sen University, Guangzhou 510275, China; fengjx23@mail.sysu.edu.cn (J.F.); \\ yingr3@mail2.sysu.edu.cn (R.Y.); yfm152797@163.com (F.Y.); jiang157@mail2.sysu.edu.cn (L.J.); \\ lsslzf@mail.sysu.edu.cn (Z.L.) \\ 2 Guangdong Provincial Key Laboratory of Geological Processes and Mineral Resources Exploration, \\ School of Earth Sciences and Engineering, Sun Yat-sen University, Guangzhou 510275, China; \\ flywangshujuan@163.com \\ 3 Center for Earth Environment \& Resources, Sun Yat-sen University, Guangzhou 510275, China \\ * Correspondence: esswsg@mail.sysu.edu.cn; Tel.: +86-136-6006-9791
}

Received: 29 December 2018; Accepted: 14 February 2019; Published: 17 February 2019

\begin{abstract}
Background and Objectives: The rapid spread of invasive Spartina alterniflora Loisel. in the mangrove ecosystems of China was reduced using Sonneratia apetala Buch.-Ham. as an ecological replacement. Here, we studied the effects of invasion and ecological replacement using S. apetala on soil organic carbon fractions and stock on Qi'ao Island. Materials and Methods: Seven sites, including unvegetated mudflat and S. alterniflora, rehabilitated mangroves with different ages (one, six, and 10 years) and mature native Kandelia obovata Sheue, Liu, and Yong areas were selected in this study. Samples in the top $50 \mathrm{~cm}$ of soil were collected and then different fractions of organic carbon, including the total organic carbon (TOC), particulate organic carbon (POC), soil water dissolved carbon (DOC) and microbial biomass carbon (MBC), and the total carbon stock were measured and calculated. Results: The growth of S. alterniflora and mangroves significantly increased the soil TOC, POC, and MBC levels when compared to the mudflat. S. alterniflora had the highest soil DOC contents at $0-10 \mathrm{~cm}$ and $20-30 \mathrm{~cm}$ and the one-year restored mangroves had the highest MBC content. S. alterniflora and mangroves both had higher soil total carbon pools than the mudflat. Conclusions: The invasive S. alterniflora and young S. apetala forests had significantly lower soil TOC and POC contents and total organic carbon than the mature K. obovata on Qi'ao Island. These results indicate that ecological replacement methods can enhance long term carbon storage in Spartina-invaded ecosystems and native mangrove species are recommended.
\end{abstract}

Keywords: biological invasion; biological replacement; mangrove; soil organic carbon; soil microbial biomass carbon; soil water dissolved carbon

\section{Introduction}

Coastal wetland ecosystems are efficient "blue carbon" (carbon stored in coastal and marine ecosystems) reservoirs [1] and they play important roles in reducing man-made $\mathrm{CO}_{2}$ emissions globally [2,3]. Due to their high productivity and soil carbon storage, mangroves are among the most carbon-rich ecosystems [4-6]. Mangroves only cover $0.5 \%$ of the coastal area and less than $0.1 \%$ of the total global continental surface area [4]. However, they contribute $10 \%-15 \%$ to the total coastal 
sediment carbon and $10 \%-11 \%$ of the carbon exported to the ocean [4-6]. More than half of the total ecosystem carbon $(49 \%-90 \%)$ in mangrove forests is stored in the soil $[5,7]$. The soil organic carbon is mainly derived from autocthonous carbon sources [8], such as tree litter and root decomposition $[4,6]$. Therefore, a vegetation composition shift would greatly affect the quality and quantity of plant material input to the soil and change the soil organic carbon pool and dynamics [9-13].

Spartina alterniflora Loisel., which is native to the eastern coast of North America, has invaded most of the mudflat areas that surround the mangrove forests of southeastern China $[10,14,15]$. A shift of the vegetation community related to plant invasion or restoration can dramatically change soil organic matter content and its dynamics $[9,16,17]$. Short term invasion of $S$. alterniflora increased the soil carbon content by 0.37-7.43 times relative to the mudflat and native saltmarsh communities [13] in the Yangtz River Estuary. The highest carbon content in a S. alterniflora community was observed at 40-60 cm depth, owing to the below ground biomass in Jiuduansha Island [9]. However, only the top $10 \mathrm{~cm}$ of soil, the organic carbon content of the mudflat was significantly increased due to invasive Spartina in mangrove ecosystems in Zhangjiang Estuary [10]. The effect of invasive species on native ecosystems can be influenced by vegetation biomass, litter production, and quality and microbiological activities $[12,13,18,19]$. Therefore, it is useful to conduct more field studies on the invasive effects of S. alterniflora on soil organic carbon dynamics in different coastal wetland ecosystems [17].

The restoration of native or natural habitat by removing invasive plants is an important method for ecosystem management [20-22]. Owing to adverse influences on the native ecosystems [15,23], different measures have been used to control the spread of $S$. alterniflora, including ecological replacement using native or exotic mangrove species [21,24,25] after physical treatment. As a fastgrowing mangrove species, the exotic Sonneratia apetala Buch.-Ham. has been successfully used to eradicate S. alterniflora and to increase the mangrove areas in China $[24,25]$. The primary goal of restoration is to reconstruct ecosystems with similar structure and function to those that were previously degraded or lost [22]. The mangrove vegetation community can be re-established [24,25] and the associated macrofaunal community and trophic relationships can also be gradually restored $[10,20,21]$ after the S. alterniflora is replaced with mangrove species. Short-term restoration of Kandelia obovata Sheue, Liu, and Yong, a mangrove species that is native to southeastern China, did not significantly enhance the soil organic carbon (SOC) stock after 15 years [21]. However, the soil carbon accumulation and stock in mangrove ecosystems can be affected by factors, such as plant species, stand age, environmental conditions, and organic matter retention and export $[5,8,14,26]$. S. apetala has shown great potential in biomass accumulation and litter production when compared to the native mangroves $[27,28]$. Thus, it is necessary to determine whether the soil carbon stock capacity can be enhanced rapidly when the invasive $S$. alterniflora is replaced by exotic $S$. apetala to assess the restoration effectiveness.

The alteration of vegetation resulting from invasion or restoration can change the source of organic material entering the soil, influence the lability and preservation of soil organic matter, and affect the carbon transformation and biogeochemical cycle $[17,29]$. The proportions of labile and recalcitrant carbon are important in the turnover and decomposition rate of total soil organic carbon and can influence long-term carbon sequestration and storage $[16,17]$. Soil particulate organic carbon (POC), water-soluble carbon (DOC), and microbial biomass carbon (MBC) are important fractions of soil labile organic matter $[17,30,31]$. DOC is the direct reservoir of nutrients that are available for soil microbial metabolism $[17,30]$. The microbial biomass in the soil regulates the transformation of soil organic matter [17]. Despite its significance, few studies have focused on the invasive effects of S. alterniflora on the dynamics of soil labile carbon. Inconsistent results have been reported between saltmarsh and mangrove ecosystems $[13,17,32]$. It is necessary to conduct additional studies on the effects of invasion and restoration on soil labile organic carbon pools to determine the process that is responsible for carbon sequestration and preservation in coastal wetland ecosystems.

The Qi'ao Island mangrove ecosystem, which is located in southeastern China, was invaded by S. alterniflora in the 1990s and eradication efforts using exotic mangrove $S$. apetala have been conducted 
since 1999 [24]. Short-term restoration of native mangroves after the removal of S. alterniflora did not enhance the SOC stock as compared to mudflats [10]. The rapidly growing S. apetala is superior in its growth characteristics to native mangrove species [33,34], and different results may occur when the S. alterniflora is replaced by $S$. apetala. In this study, we compared the content of different fractions of organic carbon and the total carbon stock of the top $50 \mathrm{~cm}$ soil to determine (1) whether the invasion of S. alterniflora increases soil organic carbon content; (2) whether S. apetala plantings can increase the soil carbon content; and, (3) which fractions of soil labile organic carbon are most impacted by the invasion of S. alterniflora and subsequent replacement by S. apetala.

\section{Materials and Methods}

\subsection{Study Area}

The Qi'ao Island Mangrove Nature Reserve is in Zhuhai City, Guangdong Province, southeastern China $\left(22^{\circ} 26^{\prime} \mathrm{N}, 113^{\circ} 38^{\prime} \mathrm{E}\right.$, Figure 1$)$. The area of the reserve is 5103.77 ha and the area of mangroves is approximately 700 ha. It has a subtropical marine monsoon climate with an average temperature of $22.4{ }^{\circ} \mathrm{C}$. Qi'ao Island has an irregular semidiurnal tide with a mean high tide level of $0.17 \mathrm{~m}$ and a mean low tide level of $-0.14 \mathrm{~m}$. The annual mean salinity of seawater is $18.4 \%[24,25]$.

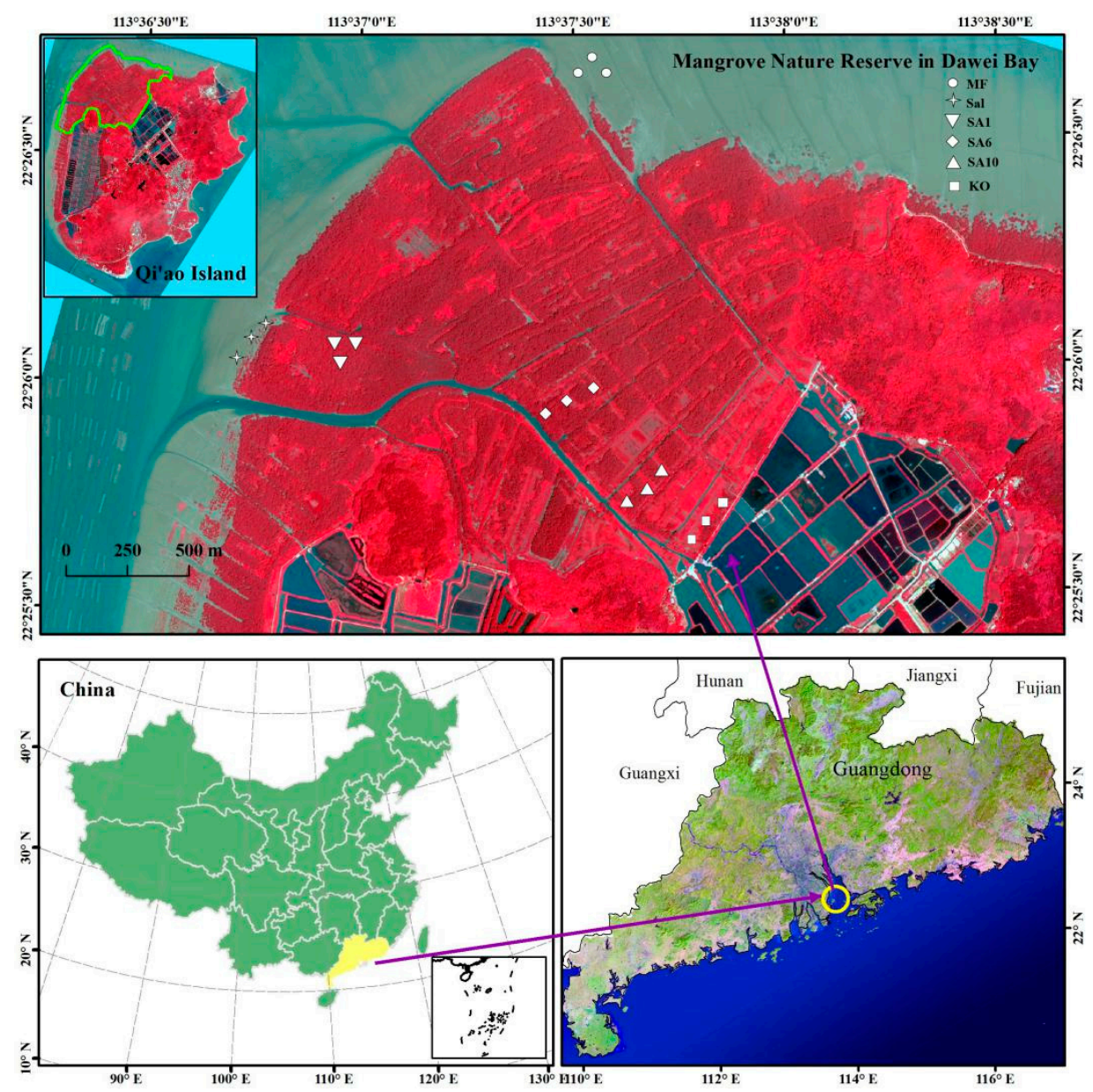

Figure 1. Map of the study sites in Qi'ao Island in Guangdong, China.

S. alterniflora invaded the gaps of the natural mangroves and mudflats of the Qi'ao Island reserve in the early 1990s. It spread and formed monocultures rapidly and it covered 227 ha by 1995 . Due to the construction of fish or shrimp ponds, some of the S. alterniflora was removed, but it remained dominant in the mudflats, with an area of 59 ha in 1999 [24]. To control the expansion of S. alterniflora, S. apetala was introduced to Qi'ao Island in an attempt to replace the S. alterniflora stands after its 
aboveground biomass was cleared (without obvious disturbance on deep soil ), which started in 1999 [24]. The S. apetala formed dense forests with a canopy about $60 \%-70 \%$ within two years and nearly and efficiently inhibited the growth of S. alterniflora. Only rare S. alterniflora individuals were observed four years after the eradication project [24]. By 2011, the mangrove area of Qi'ao Island increased to more than 300 ha and the exotic S. apetala occupied about $95 \%$ of the restored mangroves. However, there are still 15 native true mangrove species that belong to 10 families and 13 genera on this island. Therefore, an area of natural mangroves that is dominated by native K. obovata was found as a reference site in this study.

A sampling design using space as a substitution for time was developed to study the soil carbon fractions and pools that are associated with the invasion and eradication of S. alterniflora and the subsequent establishment of mangroves. Seven sampling sites with different vegetation communities were chosen according to a chronosequence: (1) pre-invaded mudflat without any vegetation (abbreviated as MF); (2) invasive S. alterniflora stands (abbreviated as Sal); (3) exotic mangrove S. apetala planted in 2010, mixing with S. alterniflora (abbreviated as SA1); (4) mangrove forests that are exclusively composed of $S$. apetala planted after the aboveground biomass of $S$. alterniflora was removed manually in 2005 (abbreviated as SA6) and in 2002 (abbreviated as SA10); and, (5) an area of natural mangroves dominated by native K. obovata was selected as reference (abbreviated as $\mathrm{KO}$ ) (Figure 1).

\subsection{Sample Collection and Measurement}

Soil core samples to $50 \mathrm{~cm}$ depth were collected from each site using a $5-\mathrm{cm}$ diameter PVC pipe during August, 2011. Three $1 \mathrm{~m} \times 1 \mathrm{~m}$ plots, separated from each other by a distance of more than $100 \mathrm{~m}$, were established within each community. Within each plot, two or three soil cores were collected and divided into four sections $(0-10 \mathrm{~cm}, 10-20 \mathrm{~cm}, 20-30 \mathrm{~cm}$, and 30-50 cm). Samples from the same depth were pooled together as a replicate. Areas with flat soil surface without obvious root and crab burrows were selected to avoid the effects of biomass input from plant root material and animals. After obvious plant material and shells were removed from the soil, the redox potential (Eh), $\mathrm{pH}$, and temperature were measured in situ using a Orion 5-star multiple function electrometer (Thermo Fisher Scientific, San Jose, CA, USA). All of the samples were divided into two subsamples. One subsample was placed into a $100 \mathrm{~cm}^{2}$ aluminum cutting ring and the other was kept in a plastic bag. All of the samples were transported to the laboratory and kept at $4{ }^{\circ} \mathrm{C}$ until analysis.

The samples in the aluminum rings were freeze-dried using a vacuum freezer (Boyikang, Beijing, China) and then weighed to calculate bulk density. The dried samples were ground into a fine powder using a mortar and pestle to pass through a $250-\mu \mathrm{m}$ sieve. Soil total organic carbon (TOC) was measured using the $\mathrm{K}_{2} \mathrm{Cr}_{2} \mathrm{O}_{7}-\mathrm{H}_{2} \mathrm{SO}_{4}$ wet oxidation method. In brief, about 0.1-0.5g dried samples were added into the test tube, and $0.1 \mathrm{~g}$ of $\mathrm{Ag}_{2} \mathrm{SO}_{4}$ and $5.00 \mathrm{ml} \mathrm{K} \mathrm{Cr}_{2} \mathrm{O}_{7}-\mathrm{H}_{2} \mathrm{SO}_{4}$ standard solution $(0.80 \mathrm{~mol} / \mathrm{L})$ were added. The tubes were heated under oil-bathing $\left(185-190{ }^{\circ} \mathrm{C}\right)$ and then kept boiling for $5 \mathrm{~min}$. Two samples of quartz sand were used as blanks. All solution and residuals were transferred to a $250 \mathrm{ml}$ beaker and kept at $60-70 \mathrm{ml}$. Subsequently, $5 \mathrm{ml} \mathrm{H}_{3} \mathrm{PO}_{4}$ solution and 2-3 drops of o-phenanthroline indicator solution were added and titrated with $\mathrm{FeSO}_{4}$ standard solution.

The POC contents of water stable aggregates were measured by the wet-sieving method using dried samples [35]. In brief, about $10 \mathrm{~g}$ soil samples were submerged in water on a $53-\mu \mathrm{m}$ screen that was contained in a shallow pan for $5 \mathrm{~min}$. Afterwards, the sieve was moved vertically 50 times in $2 \mathrm{~min}$ in water. Materials retained on the sieve were transferred to a beaker and then dried in an oven at $60{ }^{\circ} \mathrm{C}$. Subsequently, the carbon content of the dried materials (POC) was measured using $\mathrm{K}_{2} \mathrm{Cr}_{2} \mathrm{O}_{7}-\mathrm{H}_{2} \mathrm{SO}_{4}$ wet oxidation method.

DOC was extracted from $10 \mathrm{~g}$ of fresh soil sample by adding $20 \mathrm{~mL}$ distilled water to $50-\mathrm{mL}$ centrifuge tubes. The mixture was shaken for $30 \mathrm{~min}$ under $250 \mathrm{rpm}$ and then centrifuged for $10 \mathrm{~min}$ at $6000 \mathrm{rpm}$ [17]. The supernatant liquids were filtered through $0.45 \mu \mathrm{m}$ filters and the an automated TOC Analyser measured the carbon contents (Shimadzu TOC-VCPH, Kyoto, Japan). The MBC contents 
were determined by the fumigation-extraction method [36]. In brief, subsamples of $10 \mathrm{~g}$ moist soil were fumigated with ethanol-free chloroform for $24 \mathrm{~h}$ under dark conditions, then quickly transferred to centrifuge tube, extracted with $40 \mathrm{~mL} 0.5 \mathrm{M} \mathrm{K}_{2} \mathrm{SO}_{4}$, shaken for $30 \mathrm{~min}$ under $250 \mathrm{r} / \mathrm{min}$, and centrifuged for $5 \mathrm{~min}$ under $5000 \mathrm{r} / \mathrm{min}$, and then the supernatant was vacuum filtered through a $0.45 \mu \mathrm{m}$ filter. The unfumigated soil was also extracted using the same method. The carbon contents of the extracts were measured by an automated TOC Analyser (Shimadzu TOC-VCPH, Kyoto, Japan).

\subsection{Statistical Analysis}

One-way ANOVA was performed to test the significance of differences of all soil properties between different communities in each soil depth interval. Data were tested for normality and, when required, log-transformed to meet this assumption for ANOVA analysis. All of the data analyses were performed using SPSS 19.0 (IBM SPSS Statistics for Windows, IBM Corp., Armonk, NY, USA). A redundancy analysis (RDA) was used to explore the relationship between the soil carbon contents and environmental factors and ages of vegetation. The RDA was performed using the Vegan package [37] in $\mathrm{R}$ software (R 3.5.1).

\section{Results}

\subsection{Effects of Invasion and Restoration on Soil Physicochemical Parameters}

The soil temperature decreased with depth at all sites and MF had the highest temperature in the top $30 \mathrm{~cm}(p<0.05$, Table 1$)$. The soil water contents ranged from 0.4 to 0.57 and then decreased with depth in most of the sites except for Sal and SA6. KO had the highest water contents in the top $20 \mathrm{~cm}$ of soil $(p<0.05)$. For bulk density, negative relationships were observed between soil bulk density and water content $(p<0.05)$. The lowest bulk density in the surface $10 \mathrm{~cm}$ was found at the sites of $\mathrm{KO}$ and SA10 $(p<0.05)$, showing the effects of mangrove restoration. The $\mathrm{pH}$ showed no changes with depth in all sites except for MF. At each depth, MF had a higher $\mathrm{pH}$ than the other sites, except for $20 \mathrm{~cm}$, where no significant differences were found. MF had the lowest Eh values and S. alterniflora invasion significantly increased the Eh values; Sal and SA1 sites showed the largest Eh values in the surface soil $(0-10 \mathrm{~cm})$. The restoration of mangroves following the eradication of $S$. alterniflora reduced the Eh values at all depths, except for $40-50 \mathrm{~cm}$ at SA6 and $20-40 \mathrm{~cm}$ at $\mathrm{KO}$.

\subsection{Effects of Invasion and Restoration on Soil Carbon Fractions and Carbon Stock}

When compared with MF, the invasion of S. alterniflora and mangrove restoration significantly increased the soil TOC contents at all depths (Figure $2, p<0.05$ ). In the surface $0-10 \mathrm{~cm}, \mathrm{KO}$ had much larger TOC contents than the other vegetation types $(p<0.05)$. Significantly higher TOC contents at SA6 were observed than those at Sal, while no significant differences were observed for other sites. At 10-20 cm depth, KO showed the highest TOC contents and SA10 also had higher TOC contents than the other sites. Although significant differences were found for soil TOC contents among all of the vegetation communities in the $20-50 \mathrm{~cm}$ depth, the discrepancies did not show any consistent trend. The soil POC contents had similar patterns at all sites and at each depth as those for soil TOC contents. In the 0-10 cm layer, Sal showed the largest soil DOC contents among all sites $(p<0.05)$. SA10 had more substantial soil DOC contents than MF $(p<0.05)$, while no significant differences were observed among the other sites. At 10-20 cm, MF had the lowest DOC contents and KO showed larger soil DOC levels than all of the other vegetation communities $(p<0.05)$, except for Sal. The soil DOC contents for Sal and SA1 at 20-30 cm were much larger than the other sites. The growth of vegetation significantly increased the MBC contents when compared with the bare mudflat $(p<0.05)$. SA1 had the largest soil MBC contents than the other sites at each depth $(p<0.05)$. 
Table 1. Variation of soil physicochemical characteristics at different sites $(n=3$, Mean \pm SE. Different letters indicate significant differences at the same soil layer among sites).

\begin{tabular}{|c|c|c|c|c|c|c|c|}
\hline Item & Depth (cm) & MF & Sal & SA1 & SA6 & SA10 & KO \\
\hline \multirow[t]{4}{*}{ Temperature $\left({ }^{\circ} \mathrm{C}\right)$} & $0-10$ & $31.3 \pm 1.05 \mathrm{a}$ & $28.97 \pm 0.67 \mathrm{ab}$ & $29.67 \pm 0.67 a b$ & $30.30 \pm 1.18 \mathrm{ab}$ & $27.77 \pm 0.61 b$ & $28.27 \pm 1.12 b$ \\
\hline & $10-20$ & $29.53 \pm 0.45 a$ & $27.8 \pm 0.89 \mathrm{ab}$ & $27.33 \pm 0.47 \mathrm{~b}$ & $28.17 \pm 0.95 \mathrm{ab}$ & $26.87 \pm 0.65 b$ & $26.63 \pm 0.57 b$ \\
\hline & $20-30$ & $28.00 \pm 0.36 a$ & $27.27 \pm 0.55 \mathrm{ab}$ & $27.60 \pm 0.50 \mathrm{ab}$ & $28.33 \pm 0.85 a$ & $25.93 \pm 0.57 c$ & $26.13 \pm 0.46 c$ \\
\hline & $30-50$ & $27.65 \pm 0.27 a$ & $27.23 \pm 0.23 a$ & $27.72 \pm 0.34 a$ & $28.18 \pm 0.32 \mathrm{a}$ & $25.68 \pm 0.24 b$ & $25.92 \pm 0.29 b$ \\
\hline \multirow[t]{4}{*}{ Water content (\%) } & $0-10$ & $0.54 \pm 0.03 \mathrm{ab}$ & $0.46 \pm 0.02 c$ & $0.44 \pm 0.02$ & $0.48 \pm 0.03 \mathrm{bc}$ & $0.53 \pm 0.02 \mathrm{ab}$ & $0.57 \pm 0.02 \mathrm{a}$ \\
\hline & $10-20$ & $0.49 \pm 0.01 b c$ & $0.46 \pm 0.02 c$ & $0.43 \pm 0.02 \mathrm{~d}$ & $0.44 \pm 0.02 \mathrm{~d}$ & $0.51 \pm 0.01 b$ & $0.59 \pm 0.02 \mathrm{a}$ \\
\hline & $20-30$ & $0.41 \pm 0.01 \mathrm{e}$ & $0.48 \pm 0.01 b c$ & $0.47 \pm 0.01 b c$ & $0.46 \pm 0.02 \mathrm{~cd}$ & $0.52 \pm 0.01 \mathrm{a}$ & $0.42 \pm 0.01 \mathrm{de}$ \\
\hline & $30-50$ & $0.45 \pm 0.01 \mathrm{ab}$ & $0.45 \pm 0.01 \mathrm{ab}$ & $0.48 \pm 0.01 \mathrm{a}$ & $0.46 \pm 0.01 \mathrm{ab}$ & $0.48 \pm 0.01 a$ & $0.42 \pm 0.02 b$ \\
\hline \multirow[t]{4}{*}{ Bulk density $\left(\mathrm{g} / \mathrm{cm}^{3}\right)$} & $0-10$ & $0.78 \pm 0.03 \mathrm{a}$ & $0.80 \pm 0.02 \mathrm{a}$ & $0.79 \pm 0.03 a$ & $0.79 \pm 0.04 a$ & $0.65 \pm 0.02 b$ & $0.60 \pm 0.04 b$ \\
\hline & $10-20$ & $0.70 \pm 0.05 b$ & $0.82 \pm 0.04 \mathrm{ab}$ & $0.8 \pm 0.04 \mathrm{ab}$ & $0.84 \pm 0.05 a$ & $0.71 \pm 0.03 b$ & $0.52 \pm 0.04 c$ \\
\hline & $20-30$ & $0.92 \pm 0.05 a$ & $0.65 \pm 0.03 c$ & $0.71 \pm 0.03 \mathrm{bc}$ & $0.80 \pm 0.02 b$ & $0.74 \pm 0.04 b c$ & $0.95 \pm 0.05 a$ \\
\hline & $30-50$ & $0.91 \pm 0.02 \mathrm{a}$ & $0.89 \pm 0.02 a$ & $0.77 \pm 0.01 b c$ & $0.81 \pm 0.02 \mathrm{abc}$ & $0.75 \pm 0.02 c$ & $0.88 \pm 0.05 \mathrm{ab}$ \\
\hline \multirow[t]{4}{*}{$\mathrm{pH}$} & $0-10$ & $7.43 \pm 0.25 a$ & $6.84 \pm 0.22 b$ & $6.85 \pm 0.19 b$ & $7.01 \pm 0.18 \mathrm{ab}$ & $7.12 \pm 0.14 \mathrm{ab}$ & $7.05 \pm 0.17 \mathrm{ab}$ \\
\hline & $10-20$ & $6.99 \pm 0.19 a$ & $6.91 \pm 0.14 a$ & $6.85 \pm 0.16 a$ & $7.24 \pm 0.25 a$ & $6.94 \pm 0.17 a$ & $7.33 \pm 0.17 a$ \\
\hline & $20-30$ & $7.64 \pm 0.18 a$ & $6.87 \pm 0.28 c$ & $7.06 \pm 0.19 b c$ & $7.14 \pm 0.21 \mathrm{abc}$ & $7.17 \pm 0.19 a b c$ & $6.98 \pm 0.12 b c$ \\
\hline & $30-50$ & $7.63 \pm 0.07 a$ & $6.98 \pm 0.09 b$ & $7.07 \pm 0.07 \mathrm{~b}$ & $7.03 \pm 0.09 b$ & $7.25 \pm 0.08 b$ & $7.05 \pm 0.08 b$ \\
\hline \multirow[t]{4}{*}{ Eh } & $0-10$ & $-29.00 \pm 2.00 \mathrm{~d}$ & $9.00 \pm 1.00 \mathrm{a}$ & $9.00 \pm 2.00 \mathrm{a}$ & $-3.33 \pm 1.53 b$ & $-9.67 \pm 0.58 c$ & $-5.67 \pm 1.53 b$ \\
\hline & $10-20$ & $-17.33 \pm 1.16$ de & $6.00 \pm 1.00 \mathrm{a}$ & $6.00 \pm 1.00 \mathrm{a}$ & $-13.67 \pm 2.08 c$ & $-9.67 \pm 1.53 b$ & $-18.00 \pm 1.00 \mathrm{e}$ \\
\hline & $20-30$ & $-39.67 \pm 1.53 \mathrm{e}$ & $6.67 \pm 1.16 \mathrm{a}$ & $-2.00 \pm 0.00 b$ & $-8.00 \pm 2.00 c$ & $-9.67 \pm 1.53 c$ & $4.33 \pm 1.53 a$ \\
\hline & $30-50$ & $-37.00 \pm 1.18 c$ & $-2.83 \pm 1.01 \mathrm{a}$ & $-3.50 \pm 0.76 a$ & $-2.67 \pm 0.84 a$ & $-12.50 \pm 0.67 b$ & $-2.83 \pm 2.77 a$ \\
\hline
\end{tabular}



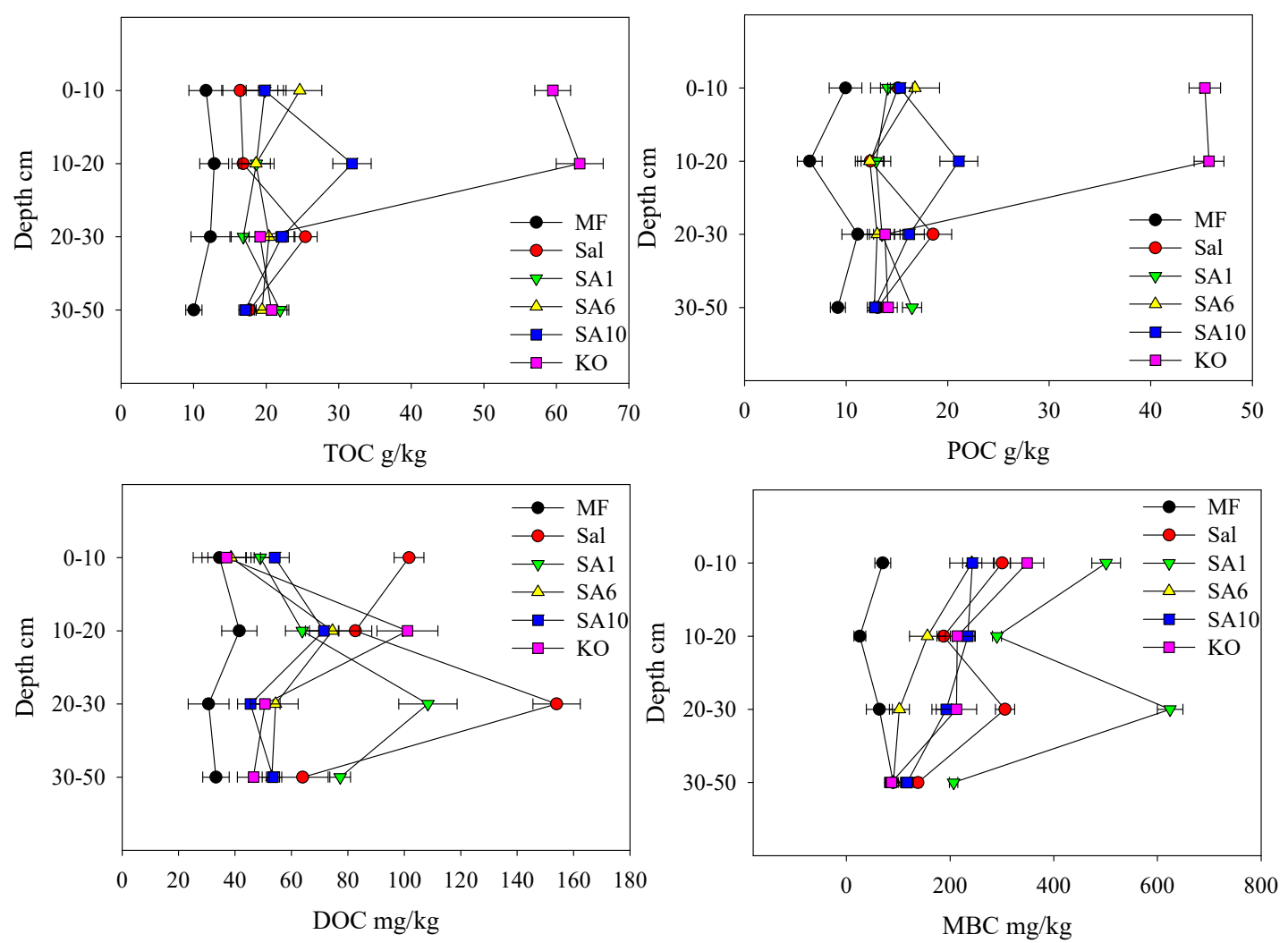

Figure 2. Vertical variation of different carbon in the sediment at different sites.

The average total carbon pool for $\mathrm{KO}(0-50 \mathrm{~cm})$ was $122.68 \mathrm{~g} \mathrm{C} / \mathrm{m}^{2}$ (Figure 3), which was significantly higher $(p<0.01)$ than all of the other sites $\left(48.08,75.14,76.37,83.16\right.$, and $77.82 \mathrm{~g} \mathrm{C} / \mathrm{m}^{2}$ for MF, Sal, SA1, SA6, and SA10, respectively). The bare MF had the lowest carbon pool when compared with all of the other sites $(p<0.01)$, while no significant differences were found among Sal and restored mangrove communities.

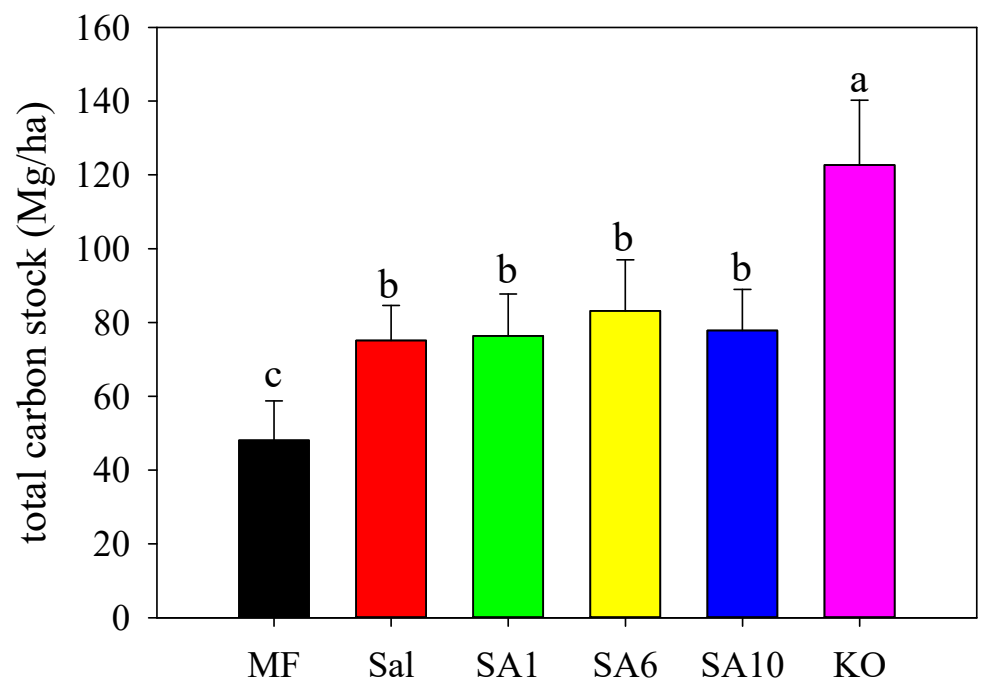

Figure 3. Total soil organic carbon stock down to $50 \mathrm{~cm}$ at different sites (error bar represents standard deviation of total carbon stock, letters indicate significant differences at $p<0.05$ ).

\subsection{Relationship between Carbon Contents and Soil Physicochemical and Plant Community Age}

The RDA results showed that the soils at $0-10 \mathrm{~cm}$ depth in different sites were well separated. MF, $\mathrm{Sal}$, and young restored mangroves were similar, while $\mathrm{KO}$ was distinct from the other sites (Figure 4). 
Axis 1 and axis 2 accounted for $55.33 \%$ and $29.13 \%$ of the total variation, respectively. The first axis was positively correlated with mangrove age, while it was negatively correlated with bulk density and age of S. alterniflora. The second axis showed a positive relationship with the age of S. alterniflora and Eh values.

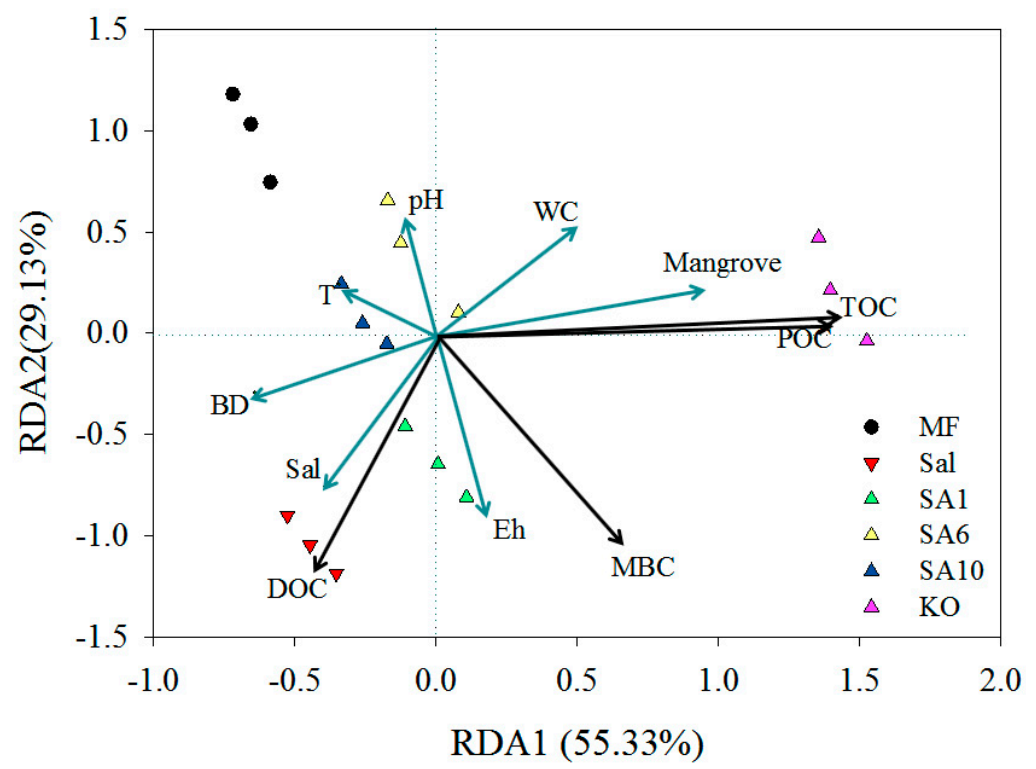

Figure 4. Redundancy Analysis (RDA) ordination showing the relationship between carbon contents of top $10 \mathrm{~cm}$ and environmental parameters of surface $0-10 \mathrm{~cm}$ soil (Sal means S. alterniflora age, Mangrove means mangrove age).

\section{Discussion}

\subsection{Effects of S. alterniflora and Restored Mangroves on Soil Organic Carbon Contents}

The soil TOC contents under S. alterniflora ranged from $16.41 \pm 1.21$ to $25.42 \pm 1.58 \mathrm{~g} / \mathrm{kg}$ in this study, which was similar to the soil SOC contents of invasive S. alterniflora in the Zhangjiang mangrove ecosystem [10], but greater than the saltmarsh ecosystem in Jiangsu [17,31,38,39]. This difference might relate to the invasion history [39] and geographic variation of the S. alterniflora biomass [14]. When compared to the unvegetated mudflat, the TOC content at 0-20 cm was increased by 50\%-107\% in all layers of soil in the 20 years following the invasion of $S$. alterniflora. This was inconsistent with previous studies, demonstrating that $S$. alterniflora could enhance the SOC content by 1.69-5.3 fold in the top $30 \mathrm{~cm}$ of soil [17] or by 73\% in the $0-50 \mathrm{~cm}$ layers of soil [39] as compared with bare mudflat. The highest soil TOC content was found at $20-30 \mathrm{~cm}$ in S. alterniflora in this study, which was probably the result of the roots being mainly distributed in the top $30 \mathrm{~cm}$ [9]. However, S. alterniflora only increased the TOC content within the surface $0-10 \mathrm{~cm}$ of soil in Zhangiiang mangrove reserve [10]. Therefore, the effects of S. alterniflora on soil carbon accumulation related to above- and belowground biomass allocation and invasive duration, together with abiotic factors, such as tidal flooding, might determine the SOC distribution related to depth $[39,40]$.

Mangrove structures are time and space dependent and carbon sequestration in mangrove soil can be determined by factors, such as climate and environmental conditions, vegetation community, and age of restored vegetation $[8,26]$. The age of mangrove is important when quantifying the multi-decadal carbon balance, owing to the fact that the carbon accumulation is more influenced by stand age than other factors $[7,26,41]$. Our RDA results also showed that the soil POC and TOC positively correlated with mangrove age (Figure 4). In the Shenzhen mangrove reserve, the younger mangroves, including exotic and native species (less than 20 years old), both showed significantly lower soil carbon content than the 70-year-old mature K. obovata ecosystem [7]. Therefore, the time series of mangrove ages, 
especially the young mangrove forests with low carbon concentrations, should be considered to accurately assess the carbon accumulation ability of the mangrove ecosystem.

The soil TOC content of 10 year old S. apetala in this study was similar to the $2.2 \%$ global median organic carbon content that was estimated for mangrove soil [6]. However, we also found that the mature K. obovata forest had 1.99-3.76 times larger soil SOC content than the S. alterniflora community and restored $S$. apetala at a depth of $20 \mathrm{~cm}$. The fast growing $S$. apetala can successfully inhibit the growth of S. alterniflora after physical removal [24,25], but it was suggested to have no superiority in soil carbon accumulation when compared with restored native mangrove species $[7,27]$. In combination with the potential risk of invasion, the planting of exotic $S$. apetala is not recommended in the future.

\subsection{Effects of Invasive S. alterniflora and Restored Mangroves on Soil Organic Carbon Fractions}

The physical structure of soil can determine the organic matter sequestration and turnover under different vegetation [42-44]. Soil aggregate structures are closely related to the amount of plant residuals and carbon contents [30] and they are influenced by biotic and environmental factors, such as vegetation type and land use changes [31,32,42]. The RDA results in our study also suggested that the soil carbon contents were significantly influenced by the invasion/eradication of S. alterniflora and the mangrove restoration (Figure 4). Coarse fractions of soil organic matter ( $>53 \mu \mathrm{m}$ ), including macro- and micro-aggregates, are generally dominant among all of the fractions of soil. They explain most of the differences in organic carbon in soil among vegetation types in natural ecosystems [30]. The plant residuals are first incorporated into the coarse fraction and are then transferred into the fine fraction $[31,45]$. The fine fraction, including silt and clay aggregates, is prominent in long-term carbon sequestration due to its high proportion of old carbon, which had low accessibility to the microbiomass $[11,31,43]$.

Soil POC contents accounted for more than $70 \%$ of soil TOC contents in this study and displayed similar variation with soil TOC content. Both of them were mainly derived from vegetation related sources. The relatively high proportion of POC showed that carbon derived from both mangroves and S. alterniflora is not easily transferred from the coarse fraction to the fine fraction due to the anaerobic conditions in coastal wetlands, and also perhaps to the refractory quality of the coarse fraction of organic carbon $[17,31,44]$. Previous research also showed that the new carbon that was derived from invasive $S$. alterniflora was mainly distributed in macro- and micro-aggregates $[16,46]$. We found that the mature mangrove forest reflected higher POC contents than the invasive S. alterniflora and short-term restored mangroves. Similar results were reported in that the coarse fractions in soil organic matter showed a larger rate of increase than the fine fraction in grassland invaded by woody plants [42]. However, further separation of soil organic matter, especially the more stable and fertile humic substances [47], and long-term studies, are needed to determine the potential of soil aggregates for carbon sequestration during the chronosequence of the invasive S. alterniflora and restored mangroves [48].

Both the S. alterniflora invasion and the subsequent mangrove restoration increased the soil DOC and $\mathrm{MBC}$ contents relative to the mudflat. Positive relationships were observed among soil DOC, MBC, and TOC contents, indicating that the input of plant materials and the soil organic matter are the main sources for soil DOC and MBC $[17,42]$. S. alterniflora had the highest soil DOC contents at $0-10 \mathrm{~cm}$ and $20-30 \mathrm{~cm}$, which were mainly derived from the aboveground biomass and root material, respectively. These results showed that $S$. alterniflora could provide more available carbon for microbial activity and then potentially accelerate the organic carbon turnover rate. The highest MBC contents were found at the SA1 site, which might have resulted from the synergistic effects of invasion and mangrove establishment that supplied additional sources for the microbial community. The enhancement of invasive S. alterniflora on the MBC and DOC can cause the rapid decomposition of soil organic carbon, which is adverse to the soil carbon stability and storage in invaded coastal ecosystems $[17,49]$. 


\subsection{Effects of S. alterniflora and Restored Mangroves on Soil Organic Carbon Stock}

The invasion of S. alterniflora significantly increased the carbon stock at $0-50 \mathrm{~cm}$ soil depth as compared to the mudflat in this study. S. alterniflora significantly improved the total soil carbon density over mudflats and native marshes in 0-100 cm depths and the influences were more prominent with time following invasion in Jiangsu, China [39]. However, spatial and temporal can affect the invasive consequence of $S$. alterniflora on carbon stock. For instance, the invasion of S. alterniflora did not yet alter the soil organic carbon pools at 0-60 cm depth in the Zhangjiang Estuary, China [10].

Mangroves generally have greater carbon storage and sequestration capability than S. alterniflora $[40,50]$, but we found no significant differences in the carbon pool between S. alterniflora and mangrove forests, except for the mature K. obovata. Similar results were reported in Australian salt marshes encroached by mangroves: belowground carbon was not enhanced in 0-14-year mangroves, while the total carbon storage increased when the mangrove ages exceeded 30 years [51]. The carbon stock of the mangroves in Qi'ao Island fell within the range that was previously reported for soil carbon stocks of mangrove ecosystems worldwide, ranging from $72 \mathrm{Mg} \mathrm{C} /$ ha in Saudi Arabia [52], to 126.14-657.61 Mg C/ha in South China [53], to the highest 2063.6 Mg C/ha in Sulawesi [54]. Although the soil carbon stocks were related to various environmental factors, such as degree of carbon inputs and export, biotic controls, and human pressures, the age of the ecosystem might be more significant in modulating mangrove carbon stocks [51].

In China, the fast growing exotic mangrove $S$. apetala has shown no advantages for carbon storage potential when compared to the native mangrove forests $[7,27,54]$. In contrast, the native mangrove $K$. obovata not only controlled the growth of S. alterniflora, but it also had a larger soil carbon pool than the invasive S. alterniflora and gradually restored the food web complexity after 14 years of restoration $[10,20,21]$. When considering the invasive potential and less prominent carbon stock ability of exotic $S$. apetala, native mangrove species are more appropriate in the future management in the control of S. alterniflora.

The carbon and nitrogen storage in coastal ecosystems may decrease if the mangrove vegetation is continually replaced by S. alterniflora [40], especially in areas that are subject to frequent anthropogenic disturbance [15]. Furthermore, the spread of S. alterniflora can increase the emissions of greenhouse gases, which is detrimental to the "blue carbon" function of coastal wetlands $[2,3,55,56]$. Therefore, a biological replacement method using mangrove species, especially native mangroves, to control S. alterniflora is recommended for the management of coastal wetlands $[21,24,25]$.

\section{Conclusions}

The growth of S. alterniflora and mangroves can significantly increase the soil TOC, POC, and MBC content at 0-50 cm depths when compared to mudflats. S. alterniflora showed the highest soil DOC contents at $0-10 \mathrm{~cm}$ and $20-30 \mathrm{~cm}$, indicating the impact of leaf litter and the developed root systems of S. alterniflora. The mixing of S. alterniflora and exotic S. apetala resulted in the highest soil MBC content in the one-year restored mangroves mixed with S. alterniflora. Both short-term invasion of $S$. alterniflora and mangrove restoration enhanced the total carbon pools of soil in comparison with mudflats. However, the S. alterniflora and young S. apetala forests had significantly lower soil TOC, POC contents, and total organic carbon pools than mature native mangroves. Biological replacement methods using mangrove species can enhance carbon storage in coastal wetland ecosystems. However, the native mangrove species are recommended.

Author Contributions: Conceptualization, S.G.W. and S.J.W.; methodology, S.G.W. and S.J.W.; formal analysis, J.F., S.J.W., R.Y., L.J., F.Y.;investigation, S.G.W. and S.J.W.; writing-original draft preparation, J.F., S.G.W.; writing-review and editing, J.F., R.Y., L.J., F.Y., Z.L.; funding acquisition, S.G.W., J.F. 
Funding: This research was funded by Natural Science Foundation of Guangdong Province, China (2016A030313188), National Natural Science Foundation of China (41706090), and Opening fund of Key Laboratory of Environment Change and Resources Use in Beibu Gulf, Ministry of Education (Guangxi Teachers Education University) (2015BGERLKF04). It was also supported, in part, by Fundamental Research Funds for the Central Universities of SunYat-sen University (17lgpy96), the Coordinate oil subsidy project of Huizhou (F2017-01-4).

Acknowledgments: We are grateful for Yuanhui Zhu for the help of map provision.

Conflicts of Interest: The authors declare no conflict of interest.

\section{References}

1. Lu, W.; Xiao, J.; Liu, F.; Zhang, Y.; Liu, C.A.; Lin, G. Contrasting ecosystem $\mathrm{CO}_{2}$ fluxes of inland and coastal wetlands: A meta-analysis of eddy covariance data. Glob. Chang. Biol. 2017, 23, 1180-1198. [CrossRef] [PubMed]

2. Yuan, J.; Ding, W.; Liu, D.; Kang, H.; Freeman, C.; Xiang, J.; Lin, Y. Exotic Spartina alterniflora invasion alters ecosystem-atmosphere exchange of $\mathrm{CH}_{4}$ and $\mathrm{N}_{2} \mathrm{O}$ and carbon sequestration in a coastal salt marsh in China. Glob. Chang. Biol. 2015, 21, 1567-1580. [CrossRef] [PubMed]

3. Chen, Y.P.; Chen, G.C.; Ye, Y. Coastal vegetation invasion increases greenhouse gas emission from wetland soils but also increases soil carbon accumulation. Sci. Total. Environ. 2015, 526, 19-28. [CrossRef] [PubMed]

4. Alongi, D.M. Carbon Cycling and Storage in Mangrove Forests. Annu. Rev. Mar. Sci. 2014, 6, $195-219$. [CrossRef] [PubMed]

5. Donato, D.C.; Kauffman, J.B.; Murdiyarso, D.; Kurnianto, S.; Stidham, M.; Kanninen, M. Mangroves among the most carbon-rich forests in the tropics. Nat. Geosci. 2011, 4, 293-297. [CrossRef]

6. Kristensen, E.; Bouillon, S.; Dittmar, T.; Marchand, C. Organic carbon dynamics in mangrove ecosystems: A review. Aquat. Bot. 2008, 89, 201-219. [CrossRef]

7. Lunstrum, A.; Chen, L.Z. Soil carbon stocks and accumulation in young mangrove forests. Soil Biol. Biochem. 2014, 75, 223-232. [CrossRef]

8. Xiong, Y.; Liao, B.; Wang, F. Mangrove vegetation enhances soil carbon storage primarily through in situ inputs rather than increasing allochthonous sediments. Mar. Pollut. Bull. 2018, 131, 378-385. [CrossRef]

9. Cheng, X.; Luo, Y.; Chen, J.; Lin, G.; Li, B. Short-term $\mathrm{C}_{4}$ plant Spartina alterniflora invasions change the soil carbon in $\mathrm{C}_{3}$ plant-dominated tidal wetlands on a growing estuarine Island. Soil Biol. Biochem. 2006, 38, 3380-3386. [CrossRef]

10. Feng, J.; Zhou, J.; Wang, L.; Cui, X.; Ning, C.; Wu, H.; Zhu, X.; Lin, G. Effects of short-term invasion of Spartina alterniflora and the subsequent restoration of native mangroves on the soil organic carbon, nitrogen and phosphorus stock. Chemosphere 2017, 184, 774-783. [CrossRef]

11. Liao, C.; Luo, Y.; Jiang, L.; Zhou, X.; Wu, X.; Fang, C.; Chen, J.; Li, B. Invasion of Spartina alterniflora enhanced ecosystem carbon and nitrogen stocks in the Yangtze Estuary, China. Ecosystems 2007, 10, 1351-1361. [CrossRef]

12. Liao, C.; Peng, R.; Luo, Y.; Zhou, X.; Wu, X.; Fang, C.; Chen, J.; Li, B. Altered ecosystem carbon and nitrogen cycles by plant invasion: A meta-analysis. New Phytol. 2007, 177, 706-714. [CrossRef] [PubMed]

13. Yang, W.; An, S.; Zhao, H.; Xu, L.; Qiao, Y.; Cheng, X. Impacts of Spartina alterniflora invasion on soil organic carbon and nitrogen pools sizes, stability, and turnover in a coastal salt marsh of eastern China. Ecol. Eng. 2016, 86, 174-182. [CrossRef]

14. Liu, W.; Maung-Douglass, K.; Strong, D.R.; Pennings, S.C.; Zhang, Y. Geographical variation in vegetative growth and sexual reproduction of the invasive Spartina alterniflora in China. J. Ecol. 2015, 84, 129-144. [CrossRef]

15. Zhang, Y.; Huang, G.; Wang, W.; Chen, L.; Lin, G. Interactions between mangroves and exotic Spartina in an anthropogenically disturbed estuary in southern China. Ecology 2012, 93, 588-597. [CrossRef] [PubMed]

16. Cheng, X.; Chen, J.; Luo, Y.; Henderson, R.; An, S.; Zhang, Q.; Chen, J.; Li, B. Assessing the effects of short-term Spartina alterniflora invasion on labile and recalcitrant $\mathrm{C}$ and $\mathrm{N}$ pools by means of soil fractionation and stable $\mathrm{C}$ and $\mathrm{N}$ isotopes. Geoderma 2008, 145, 177-184. [CrossRef]

17. Yang, W.; Zhao, H.; Chen, X.; Yin, S.; Cheng, X.; An, S. Consequences of short-term $\mathrm{C}_{4}$ plant Spartina alterniflora invasions for soil organic carbon dynamics in a coastal wetland of Eastern China. Ecol. Eng. 2013, 61, 50-57. [CrossRef]

18. Davidson, I.C.; Cott, G.M.; Devaney, J.L.; Simkanin, C. Differential effects of biological invasions on coastal blue carbon: A global review and meta-analysis. Glob. Chang. Biol. 2018, 24, 5218-5230. [CrossRef] 
19. Huang, J.; Xu, X.; Wang, M.; Nie, M.; Qiu, S.; Wang, Q.; Quan, Z.; Xiao, M.; Li, B. Responses of soil nitrogen fixation to Spartina alterniflora invasion and nitrogen addition in a Chinese salt marsh. Sci. Rep. 2016, 6, 20384. [CrossRef]

20. Feng, J.; Guo, J.; Huang, Q.; Jiang, J.; Huang, G.; Yang, Z.; Lin, G. Changes in the community structure and diet of benthic macrofauna in invasive Spartina alterniflora wetlands following restoration with native mangroves. Wetlands 2014, 34, 673-683. [CrossRef]

21. Feng, J.; Huang, Q.; Chen, H.; Guo, J.; Lin, G. Restoration of native mangrove wetlands can reverse diet shifts of benthic macrofauna caused by invasive cordgrass. J. Appl. Ecol. 2017, 55, 905-916. [CrossRef]

22. Gratton, C.; Denno, R.F. Restoration of arthropod assemblages in a Spartina salt marsh following removal of the invasive plant Phragmites australis. Restor. Ecol. 2005, 13, 358-372. [CrossRef]

23. Li, B.; Liao, C.Z.; Zhang, X.D.; Chen, H.L.; Wang, Q.; Chen, Z.Y.; Gan, X.J.; Wu, J.H.; Zhao, B.; Ma, Z.J.; et al. Spartina alterniflora invasions in the Yangtze River estuary, China: An overview of current status and ecosystem effects. Ecol. Eng. 2009, 35, 511-520. [CrossRef]

24. Chen, H.; Liao, B.W.; Liu, B.E.; Peng, C.H.; Zhang, Y.; Guan, W.; Zhu, Q.A.; Yang, G. Eradicating invasive Spartina alterniflora with alien Sonneratia apetala and its implications for invasion controls. Ecol. Eng. 2014, 73, 367-372. [CrossRef]

25. Zhou, T.; Liu, S.; Feng, Z.; Liu, G.; Gan, Q.; Peng, S. Use of exotic plants to control Spartina alterniflora invasion and promote mangrove restoration. Sci. Rep. 2015, 5, 12980. [CrossRef] [PubMed]

26. Walcker, R.; Gandois, L.; Proisy, C.; Corenblit, D.; Mougin, E.; Laplanche, C.; Ray, R.; Fromard, F. Control of "blue carbon" storage by mangrove ageing: Evidence from a 66-year chronosequence in French Guiana. Glob. Chang. Biol. 2018, 24, 2325-2338. [CrossRef] [PubMed]

27. Lu, W.Z.; Yang, S.C.; Chen, L.Z.; Wang, W.Q.; Du, X.N.; Wang, C.M.; Ma, Y.; Lin, G.X.; Lin, G.H. Changes in carbon pool and stand structure of a native subtropical mangrove forest after inter-planting with exotic species Sonneratia apetala. PLoS ONE 2014, 9, e91238. [CrossRef] [PubMed]

28. Ren, H.; Chen, H.; Li, Z.A.; Han, W. Biomass accumulation and carbon storage of four different aged Sonneratia apetala plantations in Southern China. Plant Soil 2010, 327, 279-291. [CrossRef]

29. Lian, Z.; Jiang, Z.; Huang, X.; Liu, S.; Zhang, J.; Wu, Y. Labile and recalcitrant sediment organic carbon pools in the Pearl River Estuary, southern China. Sci. Total Environ. 2018, 640, 1302-1311. [CrossRef]

30. Gunina, A.; Ryzhova, I.; Dorodnikov, M.; Kuzyakov, Y. Effect of plant communities on aggregate composition and organic matter stabilisation in young soils. Plant Soil 2015, 387, 265-275. [CrossRef]

31. Zhang, Y.; Ding, W.; Luo, J.; Donnison, A. Changes in soil organic carbon dynamics in an Eastern Chinese coastal wetland following invasion by a $\mathrm{C}_{4}$ plant Spartina alterniflora. Soil Biol. Biochem. 2010, 42, 1712-1720. [CrossRef]

32. Chen, G.; Gao, D.; Chen, G.; Zeng, C.; Wang, W. Effects of Spartina alterniflora invasion on soil carbon fractions in mangrove wetland of China. J. Water Soil Conserv. 2017, 31, 249-256, (In Chinese with English abstract).

33. Chen, L.Z.; Zeng, X.Q.; Tam, N.F.Y.; Lu, W.Z.; Luo, Z.K.; Du, X.N.; Wang, J. Comparing carbon sequestration and stand structure of monoculture and mixed mangrove plantations of Sonneratia caseolaris and S. apetala in Southern China. For. Ecol. Manag. 2012, 284, 222-229. [CrossRef]

34. Chen, L.Z.; Wang, W.Q.; Zhang, Y.H.; Lin, G.H. Recent progresses in mangrove conservation, restoration and research in China. J. Plant Ecol. 2009, 2, 45-54. [CrossRef]

35. Elliott, E.T. Aggregate Structure and Carbon, Nitrogen, and Phosphorus in Native and Cultivated Soils. Soil Sci. Soc. Am. J. 1986, 50, 627-633. [CrossRef]

36. Vance, E.D.; Brooks, P.C.; Jenkinson, D.S. An Extraction Method for Measuring Soil Microbial Biomass. Soil Biol. Biochem. 1987, 19, 703-707. [CrossRef]

37. Oksanen, J.; Blanchet, F.G.; Friendly, M.; Kindt, R.; Legendre, P.; McGlinn, D.; Minchin, P.R.; O'Hara, R.B.; Simpson, G.L.; Solymos, P.; et al. Vegan: Community Ecology Package. R Package Version 2.5-3. 2018. Available online: https:/ /CRAN.R-project.org/package=vegan (accessed on 16 February 2019).

38. Liu, J.E.; Zhou, H.; Qin, P.; Zhou, J. Effects of Spartina alterniflora salt marshes on organic carbon acquisition in intertidal zones of Jiangsu Province, China. Ecol. Eng. 2007, 30, 240-249. [CrossRef]

39. Liu, J.-E.; Han, R.-M.; Su, H.-R.; Wu, Y.-P.; Zhang, L.-M.; Richardson, C.J.; Wang, G.-X. Effects of exotic Spartina alterniflora on vertical soil organic carbon distribution and storage amount in coastal salt marshes in Jiangsu, China. Ecol. Eng. 2017, 106, 132-139. [CrossRef] 
40. Yu, X.Q.; Yang, J.; Liu, L.M.; Tian, Y.; Yu, Z. Effects of Spartina alterniflora invasion on biogenic elements in a subtropical coastal mangrove wetland. Environ. Sci. Pollut. Res. 2015, 22, 3107-3115. [CrossRef]

41. Moreno-Mateos, D.; Power, M.E.; Comin, F.A.; Yockteng, R. Structural and functional Loss in restored wetland ecosystems. PLoS Biol. 2012, 10, e1001247. [CrossRef]

42. Liao, J.D.; Boutton, T.W.; Jastrow, J.D. Storage and dynamics of carbon and nitrogen in soil physical fractions following woody plant invasion of grassland. Soil Biol. Biochem. 2006, 38, 3184-3196. [CrossRef]

43. Six, J.; Paustian, K.; Elliott, E.T.; Combrink, C. Soil structure and organic matter: I. Distribution of aggregate-size classes and aggregate-associated carbon. Soil Sci. Soc. Am. J. 2000, 64, 681-689. [CrossRef]

44. Xiong, Y.; Liao, B.; Proffitt, E.; Guan, W.; Sun, Y.; Wang, F.; Liu, X. Soil carbon storage in mangroves is primarily controlled by soil properties: A study at Dongzhai Bay, China. Sci. Total Environ. 2018, 619, 1226-1235. [CrossRef] [PubMed]

45. Desjardins, T.; Patricia, J.F.; Pando-Bahuon, A.; Girardin, C.; Patrick, L. Soil organic matter dynamics along a rice chronosequence in north-eastern Argentina: Evidence from natural ${ }^{13} \mathrm{C}$ abundance and particle size fractionation. Soil Biol. Biochem. 2006, 38, 2753-2761. [CrossRef]

46. Zhang, Y.H.; Xu, X.J.; Li, Y.; Huang, L.D.; Xie, X.J.; Dong, J.M.; Yang, S.Q. Effects of Spartina alterniflora invasion and exogenous nitrogen on soil nitrogen mineralization in the coastal salt marshes. Ecol. Eng. 2016, 87, 281-287. [CrossRef]

47. Pizzeghello, D.; Francioso, O.; Concheri, G.; Muscolo, A.; Nardi, S. Land use affects the soil C sequestration in alpine environment, NE Italy. Forests 2017, 8, 197. [CrossRef]

48. He, N.; Wu, L.; Wang, Y.; Han, X. Changes in carbon and nitrogen in soil particle-size fractions along a grassland restoration chronosequence in northern China. Geoderma 2009, 150, 302-308. [CrossRef]

49. Wang, J.; Song, C.; Wang, X.; Song, Y. Changes in labile soil organic carbon fractions in wetland ecosystems along a latitudinal gradient in Northeast China. Catena 2012, 96, 83-89. [CrossRef]

50. Bianchi, T.S.; Allison, M.A.; Zhao, J.; Li, X.; Comeaux, R.S.; Feagin, R.A.; Kulawardhana, R.W. Historical reconstruction of mangrove expansion in the Gulf of Mexico: Linking climate change with carbon sequestration in coastal wetlands. Estuar. Coast. Shelf Sci. 2013, 119, 7-16. [CrossRef]

51. Kelleway, J.J.; Saintilan, N.; Macreadie, P.I.; Skilbeck, C.G.; Zawadzki, A.; Ralph, P.J. Seventy years of continuous encroachment substantially increases "blue carbon" capacity as mangroves replace intertidal salt marshes. Glob. Chang. Biol. 2016, 22, 1097-1109. [CrossRef]

52. Atwood, T.B.; Connolly, R.M.; Almahasheer, H.; Carnell, P.E.; Duarte, C.M.; Ewers Lewis, C.J.; Irigoien, X.; Kelleway, J.J.; Lavery, P.S.; Macreadie, P.I.; et al. Global patterns in mangrove soil carbon stocks and losses. Nat. Clim. Chang. 2017, 7, 523-528. [CrossRef]

53. Liu, H.; Ren, H.; Hui, D.; Wang, W.; Liao, B.; Cao, Q. Carbon stocks and potential carbon storage in the mangrove forests of China. J. Environ. Manag. 2014, 133, 86-93. [CrossRef] [PubMed]

54. He, Z.; Peng, Y.; Guan, D.; Hu, Z.; Chen, Y.; Lee, S.Y. Appearance can be deceptive: Shrubby native mangrove species contributes more to soil carbon sequestration than fast-growing exotic species. Plant Soil 2018, 432, 425-436. [CrossRef]

55. Cheng, X.; Luo, Y.; Xu, Q.; Lin, G.; Zhang, Q.; Chen, J.; Bo, L. Seasonal variation in $\mathrm{CH}_{4}$ emission and its ${ }^{13} \mathrm{C}$-isotopic signature from Spartina alterniflora and Scirpus mariqueter soils in an estuarine wetland. Plant Soil 2010, 327, 85-94. [CrossRef]

56. Gao, G.F.; Li, P.F.; Shen, Z.J.; Qin, Y.Y.; Zhang, X.M.; Ghoto, K.; Zhu, X.Y.; Zheng, H.L. Exotic Spartina alterniflora invasion increases $\mathrm{CH}_{4}$ while reduces $\mathrm{CO}_{2}$ emissions from mangrove wetland soils in southeastern China. Sci. Rep. 2018, 8, 9243. [CrossRef] [PubMed]

(C) 2019 by the authors. Licensee MDPI, Basel, Switzerland. This article is an open access article distributed under the terms and conditions of the Creative Commons Attribution (CC BY) license (http://creativecommons.org/licenses/by/4.0/). 